\title{
GENDARME DO DIREITO: A TUTELA PENAL DA SAÚDE PÚBLICA FRENTE À PANDEMIA DO NOVO CORONAVÍRUS
}

\author{
CARLOS EDUARDO ADRIANO JAPIASSÚ ${ }^{1}$ \\ ARTUR DE BRITO GUEIROS SOUZA ${ }^{2}$
}

\begin{abstract}
RESUMO: Discorre-se sobre a saúde pública e os crimes utilizados para o enfrentamento da pandemia do coronavírus humano, em particular a infração de medida sanitária preventiva e a controvérsia sobre os complementos normativos editados pelos Estados, Distrito Federal e Municípios.
\end{abstract}

PAlAVRAS-Chave: Incolumidade pública; epidemia; norma penal em branco.

ABSTRACT: The current paper discusses public health and the crimes commited in order to confront the coronavirus pandemic, particularly the infringement of preventive health mesuare and the controversy about normative complements edited by States, Federal District and Municipalaty.

KeYWORDS: Public safety; epidemic; blank criminal rule.

\footnotetext{
${ }^{1}$ Professor Titular de Direito Penal da UERJ, Professor Associado IV de Direito Penal da UFRJ, Coordenador do PPPGD/UNESA e Vice-presidente da Associação Internacional de Direito Penal (AIDP).

2 Professor Associado de Direito Penal da UERJ, Procurador Regional da República e Coordenador do Centro de Pesquisas em Crimes Empresariais e Compliance (CPJM).
} 


\section{INTRODUÇÃO}

No final de 2019, a partir da cidade de Wuhan, na província chinesa de Hubei, iniciou-se um surto de coronavírus que alcançou, em algumas semanas, a população de todos os continentes. A primeira vítima fatal, oficialmente registrada, ocorreu naquela cidade da China, em 7 de janeiro de 2020. ${ }^{3}$ Ante a gravidade e, como visto, a sua letalidade, várias medidas foram adotadas: (1) Declaração de Emergência em Saúde Pública de Importância Internacional da Organização Mundial da Saúde (OMS), de 30/01/2020; (2) Declaração de Situação de Pandemia em relação ao novo coronavírus pela OMS, de 11/03/2020; (3) Declaração de Emergência em Saúde Pública de Importância Nacional do Ministério da Saúde (ESPIN), veiculada pela Portaria n. 188, de 04/02/2020; (4) Lei n. 13.979, de 06/02/2020, com normas para o enfrentamento da emergência de saúde pública de importância internacional decorrente do novo coronavírus; (5) Portaria n. 356, de 11/03/2020, que regulamenta e operacionaliza o disposto na Lei n. 13.979/2020, para o enfrentamento da emergência de saúde pública de importância internacional decorrente do coronavírus; e (6) Portaria Interministerial n. 5, de 17/03/2020, que dispõe sobre a compulsoriedade das medidas de enfrentamento da emergência de saúde pública previstas na Lei n. 13.979/2020, dentre outras. ${ }^{4}$

No limite, os esforços mundiais convergem para a proteção do bem jurídico saúde pública frente ao risco a que ela se encontra atualmente exposta. De fato, em razão da velocidade do contágio, oficialmente a infecção humana do COVID-19 no mundo - em números redondos - já ultrapassa quatro milhões de indivíduos contaminados, com quase trezentos mil óbitos até o dia 13/05/2020. ${ }^{5}$ Os informes de mortes, graves sequelas e de superlotação hospitalares em vários países são preocupantes e fazem lembrar de catástrofes similares, ocorridas há tempos, como a "gripe espanhola" ou pandemia do vírus influenza de 1918-1920, que contaminou um quarto da população mundial, com a perda de milhões de vidas. Atualmente, é difícil encontrar alguma pessoa que não esteja com a sua rotina afetada, de alguma forma, pelo novo coronavírus.

Enquanto médicos, cientistas e pesquisadores não encontram um tratamento eficaz, quiçá uma vacina profilática que possa afastar, de vez, os perigos do assim chamado SARS-CoV-2, a providência sanitária de rigor, além da higienização, é evitar a circulação e a aglomeração de pessoas. Numa palavra, isolamento ou distanciamento social, quarentena ou lockdown, e impedimento ou restrição de deslocamento espacial. Nesse sentido, a Lei n. 13.979/2020, anteriormente citada,

${ }_{3}^{3}$ Cf. "Sabe-se que o primeiro paciente adoeceu em Wuhan entre novembro e dezembro, mas cientistas chineses ainda buscam localizá-lo. Nos dias seguintes, pessoas buscaram atendimento com sintomas semelhantes ao de uma pneumonia viral, mas que não respondia a tratamentos comuns. Todas trabalhavam no mercado de Huanan, onde animais silvestres vivos eram vendidos em um ambiente pouco salubre." (ALVES, 2020).

${ }^{4}$ Sobre o assunto: CPJM Especial COVID-19 (2020).

${ }^{5}$ Cf. OMS (2020). 
dispõe que as autoridades poderão adotar, no âmbito de suas competências, dentre outras, as seguintes ações: (1) isolamento; (2) quarentena; e (3) restrição de entrada ou saída do País ou de locomoção interestadual ou intermunicipal.

Para a finalidade de evitar a infecção humana pelo coronavírus, a Lei considera isolamento a separação de pessoas doentes ou contaminadas, ou de bagagens, meios de transporte, mercadorias ou encomendas postais afetadas, de outros, de maneira a evitar a contaminação ou a propagação do coronavírus. Quarentena, por sua vez, é a restrição de atividades ou separação de pessoas suspeitas de contaminação das pessoas que não estejam doentes, ou de bagagens, contêineres, animais, meios de transporte ou mercadorias suspeitos de contaminação, de maneira a evitar a possível contaminação ou a propagação do coronavírus. Já restrição de entrada ou saída é o impedimento, excepcional e temporário, do ingresso ou retirada de pessoas, por intermédio de nossas fronteiras políticas, e impedimento de locomoção é a vedação da circulação entre os Estados ou entre os Municípios.

Como ocorre em situações de mudanças drásticas a serem observadas pelos integrantes do tecido social, nem sempre a conscientização e o espírito cívico são suficientes para o acatamento do comando normativo de emergência para a saúde pública. Dito de outra forma, o mais das vezes, recorre-se ao Direito Penal, como ultima ratio - ou ultimum remedium - para compelir, sob a ameaça de sanção penal, o atendimento das regras sanitárias e a adequada tutela da saúde coletiva (SOUZA, JAPIASSÚ, 2020).

Nesse contexto, devem ser examinados os tipos penais que se objetivam reforçar, com a ameaça de sanção penal, o ordenamento jurídico posto em causa diante da grave crise de saúde pública desencadeada pela pandemia do novo coronavírus. Vale dizer, os crimes de epidemia, de infração de medida sanitária preventiva e de omissão de notificação de doença. Dois outros merecem, igualmente, ser referidos: a falsificação de saneantes e o charlatanismo, todos capitulados no Código Penal.

Sendo assim, o presente artigo pretende analisar esse conjunto de incriminações se que se fazem pertinentes para a realidade social brasileira. Além do caráter preventivo-geral, próprio das normas penais incriminadoras, tem-se que muito provavelmente tais figuras típicas serão aplicadas na prática, no escopo da tutela penal da saúde pública, sendo certo que há registros de inquéritos policiais ou mesmo ações penais já deflagradas perante o nosso sistema de justiça criminal por conta da violação daqueles dispositivos penais. De toda sorte, em todas as hipóteses em questão há de incidir, por ocasião da fixação da pena judicial, a circunstância agravante do art. 61, inc. II, al. "j", do Código Penal: ter o agente cometido o crime em ocasião de calamidade pública. ${ }^{6}$

\footnotetext{
${ }^{6}$ Cf. “O art. 61, II, "j", do CP, compreende situações de calamidade pública ou de desgraça pessoal. Diferentemente do verificado na letra " $c$ ", do inc. II, do art. 61, supra, o agente não cria, mas se aproveita da dificuldade ou impossibilidade de defesa do ofendido em virtude de calamidade
} 
Antes, porém, necessário se faz examinar o bem jurídico objeto da proteção penal, o que é feito no tópico seguinte.

\section{INCOLUMIDADE PÚBLICA E SAÚDE PÚBLICA}

Saúde pública significa o estado de bem-estar físico, mental e social, relativo à generalidade das pessoas sob a tutela do Direito. ${ }^{7}$ Além da previsão em diplomas supranacionais, a saúde pública está consagrada no art. 196, da Constituição Federal de 1988: “A saúde é direito de todos e dever do Estado, garantido mediante políticas sociais e econômicas que visem a redução do risco de doenças e de outros agravos e ao acesso universal e igualitário às ações e serviços para a sua promoção, proteção e recuperação".

No Código Penal brasileiro, a saúde pública está inserida na parte relativa à tutela do bem jurídico incolumidade pública, ou seja, no Capítulo III, do Título VIII, da Parte Especial, ao lado dos crimes de perigo comum (Capítulo I) e dos crimes contra a segurança dos meios de comunicação e transporte e outros serviços públicos (Capítulo II). O gênero incolumidade - incolumitas, no latim - diz respeito ao estado da coisa incólume, firme, segura, sem colo, estaca de sustentação. Consequentemente, incólume - incolumis - é aquilo que se sustenta sozinho, sem apoio ou escoras. O complemento "pública", significa que a incolumidade - ou a segurança ou firmeza - cuida-se de expectativa esperada por todos os membros da coletividade; dirige-se a um número indeterminado de pessoas (SOUZA, JAPIASSÚ, 2020).

Numa palavra, é o estado de segurança desejável no ambiente social (PANOEIRO, NEVES, 2020).

Essa terminologia - incolumidade pública - teria aparecido, inicialmente, no Direito brasileiro a partir da entrada em vigor do atual Código Penal, em 1940. Importante ressaltar que a primeira legislação penal do Brasil independente - o Código de 1830 - nada dispunha sobre tal categoria de delito, nem mesmo sob outra nomenclatura. As formas de perigo que hoje constituem crimes autônomos - a exemplo do incêndio e da inundação - consistiam apenas em causas de

\footnotetext{
pública, oficialmente decretada ou não, ou de sua grave desventura pessoal, facilitadores da comissão do delito. Além do incêndio, naufrágio, inundação, são, também, exemplos de infortúnios coletivos: desabamento ou desmoronamento, tsunamis, epidemias, carestia, seca ou estiagem prolongada, conflitos bélicos internos ou externos etc." (SOUZA, JAPIASSÚ, 2020, p. 358359) (grifou-se).

${ }^{7}$ Segundo Nélson Hungria, o reconhecimento de uma classe de crimes contra a saúde pública remontaria a Filangieri, que teve o prestigioso apoio de Carrara, decorrendo da noção de necessidade de proteção de um grande número de indivíduos reunidos em estável consociação, circunstância na qual um direito particular (ao ar, a água, ao alimento, e assim por diante), vem a se converter em direito social ou comum a todos. Assim - segundo aquele autor -, o direito a preservação da saúde pública nasce comum a todos os cidadãos, em razão do fato mesmo da consociação. (HUNGRIA, 1959, p. 98).
} 
agravamento genérico dos demais crimes, conforme se pode observar do art. 16, item 2o , daquele Código. ${ }^{8}$

A situação se modificou com a vigência do Código Penal de 1890. Isso porque, embora não houvesse a menção direta à incolumidade pública, passaram a constar como criminosas as condutas que atentassem contra este bem jurídico. Nesse sentido, o Título III, da Parte Especial, da primeira codificação penal republicana, recebeu a nomenclatura "Dos crimes contra a tranquilidade pública". Agregue-se que, em grande parte, aquelas condutas delituosas foram reproduzidas no atual Código Penal, como mencionado no Item 80 da Exposição de Motivos do CP/1940.

Como visto, o Código Penal de 1940 reuniu os crimes contra a incolumidade pública no Título VIII, da Parte Especial, ou seja, entre os arts. 250 e 285. Nestes termos, tem-se que o delito contra a incolumidade pública é aquele cuja a conduta acarreta a probabilidade de lesão para a vida, a integridade física e o patrimônio da coletividade. Cumpre salientar que este bem jurídico difere daqueles que têm caráter individual ou individualizável, pois, aqui, a lei penal projeta seu manto protetor na direção de um número indeterminado de pessoas. ${ }^{9}$

Não se olvide que a criminalização dos crimes de perigo coletivo - como a saúde pública - pode coexistir com a incriminação de perigo individual. Por exemplo, é possível que uma pessoa infectada com o novo coronavírus descumpra o prazo de viragem de 14 (quatorze) dias no isolamento, de sorte que vá até a residência de outrem e lá dê um espirro na direção do seu rosto. Em tese, tal comportamento se

\footnotetext{
${ }^{8}$ Havia, porém, no Código Criminal de 1830, tipos penais que se enquadrariam na classificação de crimes de perigo. Estes, em sucinta explicação, são os tipos penais que descrevem comportamentos geradores de perigo real para o bem jurídico, não havendo, assim, a necessidade de dano efetivo para consumação do ilícito. Em que pese a existência de alguns crimes de perigo naquele diploma do Império, reitere-se que a incolumidade pública ainda não consistia em objeto de proteção da nossa lei penal imperial.

${ }^{9}$ A propósito, cumpre relembrar as lições acerca da classificação dos delitos entre crimes de dano e crimes de perigo. O princípio da ofensividade ou lesividade orienta o Direito Penal no sentido de que somente deverá ser tipificada a conduta que tenha potencial de arriscar (crime de perigo) ou que efetivamente ofenda (crime de dano) determinado bem jurídico penalmente relevante. Em atendimento a esse postulado, portanto, verifica-se a existência das duas espécies de crime anteriormente mencionadas. Os tipos penais presentes na legislação brasileira são majoritariamente crimes de dano. Isso porque os delitos de dano são aqueles cuja consumação exige uma efetiva lesão ao bem jurídico-penal protegido pela norma. Uma vez que é objetivo do Direito Penal a tutela dos interesses de maior valor na sociedade, faz sentido a conclusão de que a consumação de um crime dependa de ofensa ao bem jurídico que é objeto de proteção da norma. No entanto, existem circunstâncias em que a mera criação de risco de dano ao bem jurídico-penal consistirá em crime consumado. Trata-se dos crimes de perigo, os quais se consumam "com o simples perigo criado para o bem jurídico". Assim, o texto do tipo penal de perigo descreve uma conduta que será criminosa independentemente de o bem jurídico-penal não ser efetivamente lesionado, desde que tenha havido o risco de isso acontecer. (cf. SOUZA; JAPIASSÚ, 2020, p. 854).
} 
amolda ao crime de infração de medida sanitária preventiva (art. 268, do CP), em concurso com o crime de perigo de contágio de moléstia grave (art. 131, do CP).

Antes de concluir esse tópico, vale registrar que, consoante a Exposição de Motivos da Parte Especial do Código Penal, os crimes de perigo comum são aqueles que, mais nítida ou imediatamente que os das outras subclasses, criam uma situação de perigo de dano a um indefinido número de pessoas. Dessa maneira, tratando-se de crime de perigo, não há necessidade de resultado naturalístico para o seu aperfeiçoamento. Em outras palavras, não é preciso haver efetiva lesão ao bem jurídico para a sua consumação, visto que ela ocorre no momento em que há a concretização jurídica do risco de lesão para o bem jurídico tutelado, ainda que este não venha a ser atingido depois da realização do comportamento penalmente proibido.

\section{DO CRIME DE EPIDEMIA}

Epidemia - do grego epidemein, literalmente "espalhar-se pelo povo" - é doença acidental e passageira que acomete, em um curto espaço de tempo, um número significativo de pessoas (SOUZA, JAPIASSÚ, 2020). Ela se aproxima de pandemia e endemia. A pandemia é a epidemia em escala mundial, ao passo que endemia é doença que se fixa em determinada localidade. ${ }^{10}$ Como exemplo desta última podese citar a malária em certas regiões do País. Como exemplo da pandemia temos, justamente, o COVID-19, causador da Síndrome Respiratória Aguda Grave (SRAG) - na língua inglesa, Severe Acute Respiratory Syndrome (SARS).

Para a doutrina majoritária, cuida-se de crime de perigo, divergindo, contudo, os autores se se trataria de perigo abstrato - como é o entendimento de Cezar ROBERTO Bitencourt (2013) e Celso Delmanto (2010) - ou concreto - como é a opinião de Guilherme Nucci (2014) e Luiz Regis Prado (2010). Parece preferível a segunda opção, uma vez que o tipo exige que o agente cause - provoque epidemia, que os germes patogênicos se dispersem pela coletividade. Demais disso, exige-se que pessoas concretamente sejam infectadas. Acresça-se, ainda, que a epidemia é o resultado exigido pelo tipo penal que, como visto, contempla o "causar", contentando com o simples "propagar", que seria o verbo mais apropriado para um crime de perigo abstrato (SOUZA, JAPIASSÚ, 2020).

Com relação ao sujeito ativo do crime, tem-se que qualquer pessoa pode responder por epidemia, inclusive a pessoa contaminada por germes patogênicos causadores de doenças infecciosas. Por sua vez, sujeito passivo é a coletividade, titular do direito à saúde. Evidentemente, protegendo o legislador a saúde de um número indeterminado de pessoas integrantes de um mesmo grupo social, está defendendo a saúde de cada indivíduo (JESUS, 2012).

10 Cf. "Quando a difusão é extensa, atingindo várias regiões da terra, denomina-se epidemia internacional ou pandemia (Pandemei, grego, significa em massa, sobre todo o povo). Pandemia é epidemia, sem que seja a recíproca verdadeira." (FRANCO, 2001, p. 3436). 
O núcleo do tipo penal do art. 267, do $\mathrm{CP}$, pressupõe que o agente cause epidemia, propagando germe patogênico. ${ }^{11}$ Causar quer dizer provocar ou produzir. A norma exige, portanto, para a caracterização do tipo um comportamento ativo. Contudo, como se verifica com os crimes de forma geral, é cabível a punição na forma de omissão imprópria, quando há a figura do garantidor na forma do art. 13, § 2ㅇ, do CP (SOUZA, JAPIASSÚ, 2020). É o que ocorre, v.g., com o diretor de um centro epidemiológico, garantidor das normas de biossegurança para a pesquisa com organismos potencialmente letais aos seres humanos que, ao sair do trabalho, deixa de fechar um compartimento por onde escapa um germe patogênico.

O crime se consuma com a efetiva instalação da epidemia, em geral por intermédio de declarações oficiais de autoridades sanitárias, como aquelas mencionadas no início desse texto. Empiricamente, pressupõe-se certo de número de casos sucessivos, a indicar a progressiva difusão da moléstia. A tentativa é cabível, citando-se, como exemplo, o fato de a despeito da conduta do agente, o resultado não se aperfeiçoar em função da diligente ação do poder público que impede a proliferação de uma grave bactéria. ${ }^{12}$ Se da epidemia resulta morte, a pena é aplicada em dobro, bastando, para tanto, uma única morte. A multiplicidade de mortes não altera a presente causa de aumento, afastando, assim, a incidência da regra do concurso formal (JESUS, 2012).

É, ainda, admissível, a modalidade culposa de epidemia, decorrente da inobservância do dever de cuidado objetivo necessário nas circunstâncias (JESUS, 2012). É o que se constata, v.g., no irresponsável manuseio médico-hospitalar de vírus altamente contagioso, ou na concessão de alta médica, de forma indevida, para paciente portador do coronavírus humano ou, ainda, na falta de esterilização adequada do instrumental médico, assim por diante.

A pena prevista é de reclusão, de dez a 15 anos. Para a hipótese da forma qualificada do $\S 1$ o, a pena será aplicada em dobro, ou seja, de 20 a 30 anos. Já na forma culposa do $\S 2$ o a previsão é de pena de detenção, de um a dois anos, ou, se resulta morte, de dois a quatro anos. A epidemia com resultado morte é considerado crime hediondo (cf. art. $1{ }^{\circ}$, inc. VII, da Lei n. 8.072/90). ${ }^{13}$

\section{INFRAÇÃO DE MEDIDA SANITÁRIA PREVENTIVA}

11 As elementares germes patogênicos caracterizam todos os agentes nocivos produtores de epidemias, pouco importando que já estejam biologicamente identificados (cf. FRANCO, 2001).

${ }^{12}$ Neste sentido, Nélson Hungria disserta: “Dá o summatum opus desde que instalada a epidemia, isto é, desde que se apresente um certo número de casos sucessivos, a indicar a progressiva difusão da moléstia. Se, no primeiro caso, medidas sanitárias são prontamente tomadas, e com tal eficiência que vem a ser atalhado o ulterior contágio, o que se poderá identificar é a simples tentativa." (HUNGRIA, 1959, p.101).

${ }^{13}$ Releva pontuar que o crime de epidemia não segue a regra do art. 285, do CP, relativa a situações preterdolosas de morte ou lesões corporais. 
O crime de infração de medida sanitária preventiva visa fortalecer as ações de prevenção contra doenças contagiosas tomadas pelo poder público por meio daquilo que se pode denominar de gestão penal de riscos. Como dito alhures, o Direito Penal transforma-se, assim, numa espécie de gendarme do Direito ou em um cinturão de força em torno dos outros ramos jurídicos (SOUZA, JAPIASSÚ, 2020). Protege-se a incolumidade pública, em especial no que toca à preocupação com a eficácia de providências adotadas para impedir a introdução ou a propagação de doença contagiosa, como ocorre com a epidemia. ${ }^{14}$

Trata-se de crime de perigo abstrato, uma vez que basta a inobservância da determinação para a tipificação do ilícito. Por exemplo, se alguém descumpre alguma das medidas mencionadas na Introdução desse texto, comete o delito em questão, tornando-se despiciendo averiguar se houve ou não perigo de propagação do novo coronavírus para a comunidade.

Sujeito ativo do delito do art. 268, do CP, é qualquer pessoa. Cumpre atentar, porém, para o que dispõe o parágrafo único acerca dos sujeitos especiais que têm sua pena aumentada: agente de saúde pública, médico, farmacêutico, dentista ou enfermeiro. Por exemplo, responde pela forma majorada o médico que permite a reutilização e o reprocessamento de agulhas hipodérmicas, em detrimento das determinações da Agência Nacional de Vigilância Sanitária - ANVISA (FRANCO, 2001). Por sua vez, sujeito passivo é a coletividade, como ocorre em todos os ilícitos contra a incolumidade pública.

O verbo reitor do tipo é infringir, que significa violar, descumprir, referindo-se a determinação do poder público destinada a impedir introdução ou propagação de doença contagiosa. ${ }^{15} \mathrm{~A}$ conduta infringente pode ser concretizada por um comportamento comissivo - agir para transgredir a determinação - ou omissivo deixar de adotar alguma cautela exigida para a impedir a entrada ou a disseminação de doença transmissível pelo contato. De todo modo, a medida deve ter caráter obrigatório ou cogente, e não mera recomendação (PANOEIRO, NEVES, 2020).

A determinação em questão encontra-se veiculada em leis, decretos, regulamentos ou portarias emitidas pela autoridade competente. Disso se apura

${ }^{14} \mathrm{Cf}$. "A proteção que o legislador penal oferece à saúde pública, pela tipificação do crime de infração de medida sanitária preventiva, está estritamente vinculada ao dever assumido pelo Estado de atuar, mediante políticas públicas e ações concretas, para redução do risco de doenças, de acordo com o art. 196 da Constituição Federal de 1988. Sob essa perspectiva, a criminalização de condutas infratoras, descrita no art. 268, apresenta-se como um instrumento a mais de proteção da saúde, enquanto bem jurídico coletivo." (BITENCOURT, 2013, p. 322).

${ }^{15}$ Doença contagiosa é aquela assim definida pelos órgãos de saúde pública, citando-se, como exemplos, o vírus Ebola, o vírus da Dengue, da Zika, Hantavírus, vírus da Febre Amarela, vírus da Chikungunya, Influenza A H5N1 e H1N1, dentre outras. 
que se trata de norma penal em branco em sentido amplo. ${ }^{16}$ Nesse sentido, na pandemia do novo coronavírus, este dispositivo está complementado pelo art. $3^{\circ}$, da Lei n. 13.979/2020, pela Portaria n. 356/2020 do Ministério da Saúde, pela Portaria Interministerial n. 5/2020 e pelas normas emanadas pelas autoridades sanitárias estaduais, distrital e municipais, nos termos do $\S 7^{\circ}$, do art. $3^{\circ}$, da Lei $n$. 13.979/2020.

Releva salientar que a conduta de impedir a introdução compreende a violação de obstaculizar a entrada, a penetração ou estabelecimento do germe patogênico em um lugar determinado. Dessa forma, para o enfrentamento da emergência de saúde pública internacional decorrente do COVID-19, as autoridades podem restringir ou proibir a entrada de pessoas no País ou a circulação interestadual ou intermunicipal. Assim, dependendo do contexto fático, o servidor público que descumpre o dever de impedir o ingresso de alguém com sintomas do coronavírus, nos postos de controle de nossas rodovias, portos ou aeroportos, ou que permite a circulação dentro de um Estado ou dentro de um Município, incorre no crime em questão. Por sua vez, impedir a propagação é obstar a multiplicação ou a velocidade da proliferação de doença que já penetrou; é obstar a sua dispersão pela população. Assim, dependendo do contexto fático, a pessoa diagnosticada como infectada pelo novo coronavírus, que viola medida de isolamento, ou a pessoa suspeita de estar contaminada, que viola medida de quarentena, incorre no tipo penal sob consideração.

Nesse contexto, sobrelevam de importância as normas complementares de isolamento, quarentena e restrição de entrada e saída do País ou de circulação interestadual ou intermunicipal. Por exemplo, a pessoa sintomática ou já diagnosticada com o novo coronavírus, devidamente notificada da medida de isolamento, que resolver dar uma festa na sua casa para dezenas de pessoas, incorre no crime em questão. No mesmo crime incorre aquele que, diante da imposição da quarentena em uma embarcação com registro de contaminações e óbitos por COVID-19 ou em uma atividade não essencial educacional, comercial, cultural, dentre outras, resolver desembarcar clandestinamente em terra firme ou desempenhar a atividade interditada.

Para fins de segurança jurídica - vale dizer, para a tipificação do art. 268, do CP -, necessário se faz observar o disposto no art. $3^{\circ}$, seus incs. e $\$ \S$, da Lei $n$. 13.979/2020, no art. $3^{\circ}$, e seus $\S \S$, da Portaria n. 356/2020, e nos arts. $4^{\circ}$ e $5^{\circ}$, da Portaria Interministerial n. 5/2020, além das normas complementares emanadas das autoridades sanitárias estaduais, distrital e municipal, conforme o caso. Dessa feita, na hipótese de isolamento, para a configuração do crime de infração de medida sanitária preventiva, há necessidade de notificação prévia à pessoa diagnosticada como doente ou infectada acerca da compulsoriedade da medida. No caso

\footnotetext{
${ }^{16}$ Lei penal em branco (ou incompleta) e aquela cujo preceito primário da norma e formulado de maneira genérica, necessitando ser complementado por outra norma, geralmente de hierarquia inferior (SOUZA, JAPIASSÚ, 2020).
} 
anteriormente citado, o organizador da festa para várias pessoas deve receber e assinar o termo de notificação de isolamento anexo à Portaria n. 356/2020 para cumprir o período de viragem de quatorze dias de isolamento.

Tratando-se de quarentena, a compulsoriedade da medida de separação de pessoas suspeitas ou de restrição de atividade depende de ato administrativo formal e motivado da autoridade sanitária do Estado, do Município, do Distrito Federal ou do Ministro da Saúde, com ampla divulgação pelos meios de comunicação, como a Imprensa e a Internet. No exemplo acima ilustrado, a pessoa suspeita de contaminação que estava na embarcação não atracada ou que decidiu exercer a atividade não essencial, deve ter sido cientificada sobre a compulsoriedade do cumprimento da medida de quarenta dias de separação ou de inatividade.

Como se pode observar, o art. 268, do CP, se trata de lei penal em branco. Como ocorre, em geral, com normas dessa natureza, sendo revogado ou alterado o complemento, haverá a retroatividade em favor do réu. Todavia, com o presente surto do COVID-19 não há que falar de retroatividade, tendo em vista que a Lei n. 13.979/2020 e os demais diplomas infralegais que complementam o conteúdo do crime de infração de medida sanitária preventiva, cuidam-se normas excepcionais, nos termos do art. 3ㅜ, do Código Penal. Nesse sentido, dispõe o art. 8o, da Lei n. 13.979/20, que a lei vigorará enquanto perdurar o estado de emergência de saúde internacional decorrente do coronavírus responsável pelo surto de 2019-2020. ${ }^{17}$

A pena prevista para esse crime é de detenção, de um mês a um ano, cumulada com multa. Para a hipótese da forma agravada dos agentes especiais a pena é aumentada em um terço. A ação penal é pública incondicionada, cabendo transação penal ou suspensão condicional do processo. ${ }^{18}$

\section{A QUESTÃO DAS NORMAS COMPLEMENTARES AO CRIME DE INFRAÇÃO DE MEDIDA SANITÁRIA PREVENTIVA}

\footnotetext{
${ }^{17}$ Cf. Art. 3o, do CP. “A lei excepcional ou temporária, embora decorrido o período de sua duração ou cessadas as circunstâncias que a determinaram, aplica-se ao fato praticado durante a sua vigência." No mesmo sentido, o art. 12, da Portaria n. 356/2020: “O encerramento da aplicação das medidas para enfrentamento da emergência de saúde pública de importância internacional em decorrência da infecção humana pelo coronavírus (COVID-19) fica condicionada à situação de emergência de saúde pública de importância nacional, declarada por meio da Portaria n. 188/GM/MS, de 3 de fevereiro de 2020. Parágrafo único. O encerramento da emergência de saúde pública de importância nacional está condicionado a avaliação de risco realizada pela Secretaria de Vigilância em Saúde do Ministério da Saúde."

${ }^{18}$ Cf. disposto no art. 285, do CP, se de qualquer dos crimes contra a saúde pública, a exceção da epidemia, resulta lesão corporal ou morte, aplica-se o disposto no art. 258, do mesmo diploma legal. Trata-se, com efeito, de regra especial relativa a situações preterdolosas de morte ou lesões corporais, regra esta também aplicável ao crime de infração de medida sanitária preventiva. Portanto, se do fato doloso, resultar lesão corporal de natureza grave, a pena é aumentada da metade. Se resulta morte, é aplicada em dobro.
} 
Conforme indicado, o crime de infração de medida sanitária preventiva é norma penal em branco, podendo seu complemento ter caráter temporário ou permanente, bem assim ser emanado de autoridade competente federal, estadual ou municipal (HUNGRIA, 1959). Nesse contexto, como lecionado por Panoeiro e NEVES (2020), a correta exegese do tipo penal do art. 268, do CP frente a pandemia do coronavírus humano depende da apreciação de um conjunto de disposições normativas, bem assim das decisões, ainda que de natureza cautelar, proferidas e publicadas pelos nossos tribunais.

Sobre o assunto, o Supremo Tribunal Federal (STF), enfrentou a questão da adoção de medidas sanitárias por parte de Estados, Distrito Federal e Municípios, para evitar a dispersão do novo coronavírus. Na apreciação da ADPF 672, o Ministro Relator Alexandre de Moraes afirmou a competência concorrente entre União, Estados e Municípios para a promoção de ações dirigidas a contenção da situação de calamidade gerada pela pandemia do COVID-19, em especial com relação (1) ao funcionamento de atividades econômicas, e (2) as regras de aglomeração. Segundo o Relator, "[e]m relação à saúde e assistência pública, inclusive no tocante à organização do abastecimento alimentar, a Constituição Federal consagra, no termos dos incs. II e IX, do art. 23, a existência de competência administrativa comum entre União, Estados, Distrito Federal e Municípios." ${ }^{19}$

No mesmo sentido, o Plenário do STF ratificou a liminar concedida na ADI 6341, que se voltava contra as alterações promovidas pela Medida Provisória n. 926/2020 na Lei n. 13.979/2020. Assim, por maioria, os Ministros deram interpretação conforme a Constituição ao $\S 9^{\circ}$, do art. $3^{\circ}$, da Lei n. 13.929/2020, a fim de explicitar que, preservada a atribuição de cada esfera de governo, nos termos do inc. I, do art. 198, da Constituição, o Presidente da República poderá dispor, mediante decreto, sobre os serviços públicos e atividades essenciais.

Por outro lado - como bem lembrado por Panoeiro e NEVES (2020) -, o Superior Tribunal de Justiça (STJ), tem negado salvo conduto (habeas corpus), em cognição sumária, destinado a viabilizar a livre circulação de pessoas sem a responsabilização criminal pelo delito do art. 268, do CP.

Dessa forma, observa-se, de um lado, a epidemia de caráter nacional e, de outro, o reconhecimento legal e judicial da competência concorrente da União, Estados, Distrito Federal e Municípios, para a imposição de restrições que, se descumpridas, poderão ensejar a violação do crime de infração de medida sanitária preventiva.

\footnotetext{
${ }^{19}$ ADPF n. 672. STF. Plenário. Relator Min. Alexandre de Moraes. Púb. DJe de 14/04/2020. Prossegue o Relator: "Dessa maneira, não compete ao Poder Executivo federal afastar, unilateralmente, as decisões dos governos estaduais, distrital e municipais que, no exercício de suas competências constitucionais, adotaram ou venham a adotar, no âmbito de seus respectivos territórios, importantes medidas restritivas como a imposição de distanciamento ou isolamento social, quarentena, suspensão de atividades de ensino, restrições de comércio, atividades culturais e à circulação de pessoas, entre outros mecanismos reconhecidamente eficazes para a redução do número de infectados e de óbitos (...)."
} 
Sendo assim, para fins de segurança jurídica - em razão do princípio do nullum crimem, nulla poena sine lege certa -, necessário se faz delimitar o alcance das normas emanadas de cada integrante daquele "condomínio legislativo", conforme a expressão utilizada pelo Procurador-Geral da República no Parecer oferecido à ADI 6341 (PANOEIRO, NEVES, 2020).

Nesses termos, para o enfrentamento da pandemia do COVID-19, tem-se que compete à autoridade competente do Poder Executivo federal editar normas gerais que busquem a coordenação nacional; às autoridades dos Estados e Distrito Federal editar normas temáticas de interesse regional e em suplementação das normas federais; e às autoridades municipais legislar sobre matéria de interesse local. Considerando que as principais medidas para o enfrentamento da situação de emergência de saúde pública de importância internacional decorrente do coronavírus são (1) o isolamento de pessoa doente ou contaminada, (2) a quarentena de pessoa suspeita ou a interdição de atividade não essencial, e (3) o impedimento de entrada ou saída do País ou a locomoção interestadual e intermunicipal, necessário se faz averiguar o que cada autoridade pode determinar, através do complemento normativo, visto que se exorbitar o âmbito do permitido não acarretará a tipificação do crime do art. 268, do CP. Dito de outra forma, a atuação da autoridade fora da competência constitucional acarreta a ilegitimidade da imputação de violação do delito de infração de medida sanitária preventiva.

Demais disso, vale repetir o que foi dito acima, acerca da distinção entre norma complementar de natureza obrigatória e norma complementar de natureza recomendativa. O descumprimento da primeira acarreta a tipificação do crime sob consideração, ao passo que o desatendimento da segunda, não caracteriza. Por exemplo, é possível que seja editada medida sanitária - por qualquer das três esferas políticas - recomendando aos homens adultos que façam a barba, para diminuir o risco de infecção do novo coronavírus, facilitando, assim, a higienização do rosto, o uso da máscara e a redução do hábito de colocar a mão no rosto. Todavia, sendo mero aconselhamento, não possuiria obrigação de norma penal caso alguém decidisse não raspar os pelos faciais.

Outro exemplo - menos prosaico - sobre caráter obrigatório foi apresentado por Panoeiro e NEVES (2020). Segundo eles, a medida de isolamento de doentes ou contaminados depende de ato do Ministério da Saúde que fixasse o seu conteúdo, condicionado, porém, ao exame laboratorial e clínico que ateste positivo para a moléstia. Isso foi complementado pela Portaria n. 356/2020, que prevê duas formas de isolamento: (1) por determinação médica e (2) por recomendação do agente de vigilância epidemiológica. No primeiro caso, não há dúvida de que o descumprimento do isolamento prescrito por médico - acompanhado do termo de consentimento livre e esclarecido do paciente - dá ensejo a tipificação do crime do art. 268, do CP, ante a sua natureza cogente. Diversamente, o descumprimento da medida de isolamento determinada por recomendação do agente de vigilância, no curso da investigação epidemiológica, por meio da notificação expressa à pessoa 
contactante, não tipifica o crime, por não ter caráter cogente. Segundo aqueles autores:

\begin{abstract}
“A Portaria n. 356/2020, ao prever duas formas de isolamento, uma por determinação médica e outra por recomendação do agente de vigilância epidemiológica, ao que parece, exorbita os limites legais. (...) Outrossim, a supostamente equivocada referência feita na Portaria Interministerial 5/2020 à comunicação do agente quanto à compulsoriedade da medida, mas referindo-se ao termo de consentimento informado relacionado ao isolamento por 'recomendação' em nada alteram a substância do acima alinhado. (...) É que nenhuma das duas portarias poderia exorbitar o âmbito do isolamento previsto na lei, o qual, como é intuitivo, depende de comprovação por meio de exame laboratorial de sua condição. Não há crime se estamos diante de mera recomendação, o pressuposto do delito é a compulsoriedade e a condição de infectado."
\end{abstract}

No tocante a medida de quarentena - como visto acima - o complemento normativo do crime do art. 268, do CP, preconiza que ela deve ser determinada para a restrição de atividades não essenciais ou separação de pessoas suspeitas de contaminação das pessoas que não estão doentes. Neste último caso, deve-se distinguir pessoas suspeitas de pessoas já diagnosticadas com a moléstia, como ocorre no caso de isolamento. Conforme já exemplificado, quem se encontra em uma embarcação onde foi registrado casos de pessoas infectadas ou óbitos por COVID-19, é suspeita de estar com a moléstia, considerando seu alto potencial de transmissibilidade. Mas não há certeza. De toda sorte, com a edição do ato devidamente motivado, ela deve cumprir a quarentena, sob pena de se vê incursa no crime em questão.

Dessa forma, como bem observado por Panoeiro e NEVES (2020),
“(...) Parece ser desarrazoada a prisão de pessoas que se encontrem caminhando na orla da praia da cidade do Rio de Janeiro por estarem, em tese, violando a quarentena, pois não há critério legal ou administrativo federal para qualificá-las como suspeitas ou, alternativamente, prova que estejam contaminadas e, portanto, devam ser submetidas a isolamento."

Com relação à quarentena para o impedimento ou restrição de atividades, cuida-se de questão enfrentada pelo Supremo Tribunal Federal, nos julgados acima mencionados. O Poder Executivo federal pode dispor sobre a quarentena em atividades, podendo, inclusive, dispor, mediante decreto, sobre serviços públicos e atividades essenciais (cf. $\S 9^{\circ}$, do art. $3^{\circ}$, da Lei n. 13.929/2020, incluído pela MP n. 926/2020). Contudo, não pode adentrar na esfera de competências das demais 
entidades federativas. Nesse panorama, tem-se que o funcionamento do comércio local e da educação básica ou infantil é matéria da competência municipal que pode, consequentemente, determinar a quarentena nessas atividades. O mesmo se diga com relação ao funcionamento do comércio intermunicipal ou da educação no ensino médio, da competência que é dos entes estaduais e distrital.

É certo que a complexidade da presente temática, bem assim a multiplicidade de fontes complementares da norma penal incriminadora do art. 268, do CP, pode acarretar - ou já está acarretando - perplexidades ou dificuldade de compreensão por parte dos destinatários na norma. Ademais, há a disparidade de critérios para a adoção da quarentena, perceptível entre os entes legitimados para expedição do complemento da norma penal em branco. Assim, prosseguem Panoeiro e NEVES (2020):

“(...) hipoteticamente, caso reputada válida a decretação da quarentena pelo prefeito de determinado município e estabelecida a obrigatoriedade de uso de máscaras de proteção para a circulação, sob o ponto de vista da interpretação a ser conduzida, em tese, o sujeito que circula sem máscara poderia ser preso por violar a norma municipal relativa à quarentena. De outra banda, a adoção de outro tipo de quarentena em município vizinho já não importará na incriminação de tal conduta, embora a pandemia seja a mesma e de caráter nacional."

A esse cenário se agrega a falta de uma testagem em massa da população brasileira, que impossibilita uma clara compreensão dos indivíduos que devem se submeter às regras de isolamento, quarentena ou de impedimento de circulação interestadual e intermunicipal.

\section{O CRIME DE OMISSÃO DE NOTIFICAÇÃO DE DOENÇA}

Ao tempo do Código Penal de 1890, a omissão de notificação de doença aparecia como contravenção de perigo comum, então tipificada de forma mais restrita, pois somente se aplicava ao médico-clínico e às doenças infecciosas, sujeitando-a a simples pena pecuniária. O Código Penal de 1940 elevou a conduta ao status de crime, estendendo-a para qualquer médico e para toda doença considerada de notificação compulsória (HUNGRIA, 1959).

Nestes termos, protege-se a incolumidade pública, no que concerne à saúde pública exposta a perigo pela conduta ilícita do médico. Crime omissivo que é, apresenta, o art. 269, do CP, uma notável exceção ao sigilo médico, impondo-se um imperativo penal no sentido da comunicação à autoridade competente (HUNGRIA, 1959).

Como se vê, o sujeito ativo desse tipo penal é apenas o médico, já que se trata de crime próprio e exige do agente uma condição ou qualidade especial. Já o sujeito passivo é a coletividade, exposta a perigo por meio das doenças não notificadas ou 
subnotificadas, situação que sobreleva de gravidade em caso de pandemia, como ocorre na atualidade com o coronavírus humano.

A conduta proibida é deixar de denunciar ou noticiar, isto é, desatender ao comando cogente da norma penal. Deixar de é expressão indicativa de crime omissivo próprio. No caso, o médico se omite do dever de denunciar à autoridade pública a doença de notificação compulsória, pouco importando a forma pela qual travou contato com a ocorrência da mesma, como, por exemplo, por meio de simples exame clínico no seu consultório, por ocasião de uma necropsia ou da ação sanitária de visita a domicílios, entre outras hipóteses (SOUZA, JAPIASSÚ, 2020).

A semelhança do anterior, cuida-se de crime de perigo abstrato. $O$ legislador presume o risco pela simples ausência da notificação do médico, que repercute negativamente nas ações preventivas contra o surgimento ou a propagação de doenças, como ocorre no caso da epidemia. Demais disso, é norma penal em branco ou aberta, cujo complemento - o rol das moléstias de notificação obrigatória - vem a ser dado por normas emanadas da autoridade competente.

Nesse sentido, a Portaria de Consolidação n. 4/2017, do Ministério da Saúde, apresenta a lista nacional de notificação compulsória de doenças, agravos e eventos de saúde pública. Dentre as doenças que aquela Portaria arrola como de notificação obrigatória está a Síndrome Respiratória Aguda Grave (SRAG) associada ao Coronavírus ou SARS-CoV, consoante a relação atualizada pela Portaria MS n. 264/2020.

Dessa feita, ao se deparar com um caso suspeito do novo coronavírus, o médico tem o dever legal de coletar duas amostras de materiais respiratórios, como aspiração de vias aéreas ou indução de escarro, para identificar a doença. Em seguida, deve reportar o caso para o Centro de Informações Estratégicas em Vigilância em Saúde (CIEVS), diretamente ou por intermédio da secretaria estadual ou municipal de saúde. Pode, ainda, o médico se valer do canal de contato telefônico ou eletrônico para as notificações de COVID-19. Em paralelo à notificação compulsória, os materiais coletados deverão ser enviados ao Laboratório Central de Saúde Pública (Lacen) para a realização de prova e contraprova, além do envio de uma das amostras para o Centro Nacional de Influenza (NIC) e a outra deve ser enviada para análise metagenônica.

Como dito, o art. 269, do CP, se trata de norma penal em branco. Como cediço, o complemento da norma penal em branco segue as regras gerais da retroatividade in mellius, salvo se excepcionais ou temporárias, como ocorre no caso tratado pela Lei n. 13.979/2020 que, conforme já mencionado, possui natureza de norma excepcional, nos termos do art. $3^{\circ}$, do Código Penal.

Por outro lado, é possível existir conflito aparente entre o dever de notificação compulsória de doença e o dever do médico de velar pelo sigilo profissional (art. 154, do CP). Sobre o assunto, a doutrina assinala que embora se verifique hipotética violação do segredo profissional, não se configura o crime do art. 154, do $\mathrm{CP}$, devido à ausência do elemento normativo do tipo - agir sem justa causa -, 
excluindo, assim, a tipicidade da conduta do médico comunicante (BITENCOURT, 2013).

O delito se consuma com a não comunicação da ocorrência da doença, no prazo estipulado no complemento normativo. No caso do coronavírus humano, o prazo para a notificação é de 24 (vinte e quatro) horas, contado a partir da suspeita inicial da síndrome gripal ou respiratória ou do óbito. Conforme adiantado, cuida-se de crime omissivo próprio, não cabendo, assim, a possibilidade de tentativa, pois, ou bem o agente atua até o último instante permitido - e estar-se-á diante de um indiferente penal - ou bem se omite, concretizando-se, assim, o delito.

A pena é de detenção, de seis meses a dois anos, cumulada com multa. A ação penal é pública incondicionada, cabendo transação penal ou suspensão condicional do processo.

\section{FALSIFICAÇÃO, CORRUPÇÃO, ADULTERAÇÃO E ALTERAÇÃO DE SANEANTES}

Em 1998, ocorreu outra grave crise na saúde pública brasileira. Na ocasião, houve uma grande falsificação de medicamentos que causou intranquilidade na nossa população. A resposta dada ante o clamor público foi a edição da Lei $\mathrm{n}$. 9.677/1998, que alterou os crimes tipificados entre os arts. 272 e 278, do Código Penal, sendo que a tônica foi o recrudescimento das penas. Essa opção do legislador foi alvo de polêmicas, tendo sido por muitos apontada a violação de princípios constitucionais em matéria penal, tais como a proporcionalidade e a proibição do excesso punitivo. ${ }^{20}$

Dentre as diversas mudanças, foi dada nova redação ao art. 273, do CP falsificação, corrupção, adulteração ou alteração de produto destinado a fins terapêuticos ou medicinais -, com a elevação das penas cominadas e a inserção de figuras equiparadas nos $\S 1^{\mathrm{o}}$-A e $\S 1^{\circ}$-B. Como dito alhures, as formas equiparadas também foram objeto de críticas doutrinárias, sendo certo que os tribunais reconheceram a relevância da questão em causa (SOUZA, JAPIASSÚ, 2020). ${ }^{21}$

Seja como for, dentre as hipóteses que o legislador considerou equivalente a falsificação, corrupção, adulteração ou alteração de medicamentos está, justamente, a contrafação de saneantes. Nesse prisma, como exposto no início desse trabalho,

${ }^{20}$ Cf. "Nossos doutrinadores tecem severas críticas ao legislador, pois as modificações introduzidas, em razão da desproporção das penas ante condutas de lesividade flagrantemente diversa, desatenderam ao princípio constitucional da proporcionalidade." (FRANCO, 2001, p. 3464). Para Celso Delmanto et al, além da desproporcionalidade entre o desvalor da conduta e do seu resultado, a desproporcionalidade da pena fica evidente quando comparada com a pena de outros delitos, incontestavelmente mais graves. (DELMANTO, 2010).

${ }^{21}$ Sobre o assunto, por ocasião do julgamento do RE 979962, no Plenário Virtual, o Supremo Tribunal Federal reconheceu a repercussão geral para o fim de examinar a constitucionalidade do art. 273, do $\mathrm{CP}$, em razão de alegada violação ao princípio da proporcionalidade pela cominação de pena elevada e idêntica para condutas completamente distintas (Cf. http://www.stf.jus.br/portal/cms/verNoticiaDetalhe.asp?idConteudo=386710, acessado em maio de 2020). 
dentre as principais recomendações sanitárias destinadas a evitar a propagação do COVID-19, está a higienização de ambientes, objetos e de partes do corpo, como as mãos, com preparação alcóolica, conforme consta de recomendações da ANVISA. ${ }^{22}$

Em razão da pandemia do novo coronavírus, tem sido observados episódios de falsificação de saneantes, considerando a grande procura de produtos dessa natureza por parte da população. Cite-se, como exemplo, o episódio ocorrido em Osasco/SP, no qual policiais civis, depois de abordar um homem com uma caixa de álcool gel de origem suspeita, conseguiram descobrir uma "central de distribuição para embalar e fracionar o produto". ${ }^{23}$

Com efeito, tais fatos se enquadram no tipo penal sob comento. Contudo, há controvérsia a respeito da sanção a ser imposta ao infrator. Isso porque, como adiantado, os tribunais têm considerado inconstitucional a pena cominada ao art. 273, do Código Penal, ou seja, reclusão de dez a quinze anos, além de multa. O Superior Tribunal de Justiça (STJ) reconheceu a inconstitucionalidade do preceito secundário do crime tipificado no art. $273, \S 1^{\circ}-\mathrm{B}$, do $\mathrm{CP}$, autorizando a aplicação analógica das penas previstas para o crime de tráfico de drogas. Demais disso, para aquele Tribunal, é possível a incidência da causa de diminuição de pena prevista no $\S 4^{\circ}$, do art. 33, da Lei n. 11.343/2006, no cálculo da pena dos condenados pelo delito anteriormente mencionado. ${ }^{24}$

Na mesma esteira, ambas as Turmas do Supremo Tribunal Federal (STF) já afirmaram a constitucionalidade do crime do art. 273, § 10-B, do CP. Todavia, registraram que a pena a ele cominada seria desproporcional, motivo pelo qual deve ser aplicada aquela prevista no tipo do art. 33 da Lei de Drogas. ${ }^{25}$ Demais disso, como já adiantado, o STF reconheceu repercussão geral para decidir sobre a constitucionalidade da pena cominada ao art. 273, do CP.

\section{Charlatanismo}

${ }^{22}$ Cf.https://www20.anvisa.gov.br/segurancadopaciente/index.php/publicacoes/category/higieniza cao-das-maos, acessado em maio de 2020.

${ }^{23}$ Segundo a Secretaria de Segurança Pública de São Paulo, a central funcionava em uma casa no bairro de Jaraguá, na capital paulista. Durante o flagrante foram apreendidas 15 caixas fechadas contendo 25 frascos de álcool em gel de $500 \mathrm{ml}$ falsificados, 11 galões de 50 litros com substância para envasar os frascos vazios, além de diversos outros materiais de insumo para manipulação dos produtos, com a prisão de um suspeito. (Cf. https://agenciabrasil.ebc.com.br/geral/noticia/2020-04/policia-civil-descobre-central-de-alcoolem-gel-falsificado-em-sp, acessado em maio de 2020).

${ }^{24}$ Cf. AgRg no AgRg no AREsp 1610153/PE. STJ. 5 ${ }^{\mathbf{a}}$ T. Relator Min. Jorge Mussi. Pub. DJe de 28/04/2020. Sobre o assunto, vide o leading case: AI no HC 239363/PR. STJ. Corte Especial. Relator Min. Sebastião dos Reis Jr. Pub. DJe de 10/04/2015.

${ }^{25}$ Cf. REAgR1105421/SP. 2a T Rel. Min. Gilmar Mendes. Pub. DJe de 21/02/2019; REAgR 662.090/SP.

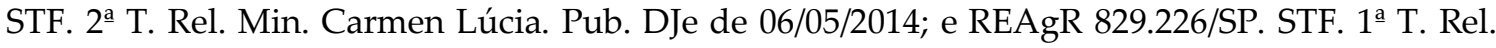
Min. Luiz Fux. Pub. DJe de 06/03/2015. 
Charlatão - do francês charlatan e do italiano ciarlatano - é o indivíduo falador, impostor, que se vende por erudito. Demais disso, é quem inculca panaceias ou drogas de muito préstimo ou segredos da medicina. Consequentemente, charlatanismo é expressão cuja origem significa falar muito, tagarelar, inculcar ou propagar a cura de moléstias (SILVA, 1858).

No passado, atribuía-se o adjetivo de charlatão àqueles que, em feiras ou praças públicas, faziam propaganda dos produtos que vendiam, em voz alta, exagerando suas qualidades ou propriedades terapêuticas. Posteriormente, limitou-se a denominar as pessoas que, de má-fé, iludiam os inocentes, fazendo-os crer em curas milagrosas, por intermédio de processos infalíveis (SOUZA, JAPIASSÚ, 2020).

Como os tipos penais anteriores, o crime de charlatanismo tutela a saúde da coletividade. Indiretamente, protege a fé pública e o patrimônio individual, considerando a credulidade de quem se deixa levar pelas promessas de cura ou pela compra de falsos remédios ou tratamentos medicinais. Trata-se de delito de perigo abstrato, que se perfaz independente de qualquer resultado ulterior. Não importa, pois, se o infrator conseguiu convencer alguém com seus atos, gestos, palavras, produtos, e assim por diante (SOUZA, JAPIASSÚ, 2020).

Pode responder como sujeito ativo do crime de charlatanismo qualquer pessoa, inclusive eventual médico inescrupuloso. Por sua vez, sujeito passivo é a coletividade, bem como o indivíduo circunstancialmente iludido pelo charlatão.

Na forma prevista no art. 283, do $\mathrm{CP}$, cuida-se de crime de ação múltipla. A primeira conduta tipificada é inculcar, que significa apregoar, aconselhar, sugerir com ênfase, propagandear. A segunda conduta é anunciar, que significa o mesmo que publicar, avisar, transmitir até mesmo pela mídia etc. O objeto material é a cura por meio secreto ou infalível. O charlatão propõe ou divulga a cura de doenças por processos ou remédios que somente ele tem conhecimento ou então que diz ser infalível. O meio secreto é aquele oculto, ignorado. Já o meio infalível é o que possui eficácia absoluta. A obscuridade e a infalibilidade estão nas antípodas do conhecimento científico, merecendo, no caso, a reprova penal (BITENCOURT, 2013).

No caso, o criminoso se vale do embuste ou para obter vantagens da coletividade, não necessariamente de natureza econômica, muito embora, na maior parte dos casos o agente objetive auferir ganhos ilícitos. Cite-se, como exemplo, a conduta do Pastor Valdemiro Santiago, líder de uma igreja pentecostal que, em maio de 2020, anunciou nas redes sociais - mais especificamente no YouTube - a "cura" para o novo coronavírus, por meio da venda de sementes de feijão pelo valor de $\mathrm{R} \$ 1.000,00$ (mil reais), em dinheiro vivo ou cartão de crédito. No caso, o Ministério Público Federal solicitou àquela empresa a retirada do ar dos vídeos, além de enviar notícia-crime ao Ministério Público do Estado de São Paulo, para apuração do crime de charlatanismo em concurso formal com estelionato (BATISTA JR., 2020). 
A pena é de detenção, de três meses a um ano, além de multa. Cabe transação penal e suspensão condicional do processo.

\section{CONCLUSÃO}

A pandemia de proporções inimagináveis, como a causada pelo novo coronavírus produziu uma situação há muito não vista pela humanidade. $\mathrm{O}$ número de pessoas infectadas, de mortes e de países atingidos e submetidos a medidas sanitárias impressiona e assusta.

Nesse contexto, não seria esperado que os Estados não recorressem ao Direito Penal e à severidade da pena como forma de impelir os indivíduos à observância das determinações que pretendem auxiliar na contenção da doença e, portanto, salvar vidas. Independentemente do acerto ou do erro das medidas sanitárias impostas, concordando-se ou não com elas, parece evidente que é necessário revisitar os crimes contra a saúde pública e os tipos penais aí previstos, visto que a excepcionalidade da pandemia cria oportunidade de uma série de condutas que podem ser danosas à sociedade como um todo.

A questão, nesse caso, como, de resto, nas discussões relativas ao Direito Penal, é o equilíbrio para lidar com condutas reprováveis, sem excessos indesejáveis.

Além disso, faz-se necessário que haja uma ação coordenada da União, dos Estados e dos Municípios, responsáveis por editar normas complementares. Por conta de sua competência concorrente, iniciativas contraditórias podem afetar a segurança jurídica e criar dificuldades para a observância e para a aplicação das normas penais.

\section{REFERÊNCIAS}

ALESSI, Gil. Contra “o feijão que cura” coronavírus e outras mentiras, profissionais de saúde cobram ação das gigantes da tecnologia. In https://brasil.elpais.com/brasil/2020-05-12/contra-o-feijao-que-cura-coronavirus-eoutras-mentiras-profissionais-de-saude-cobram-acao-das-gigantes-datecnologia.html.

ALVES, Ana Rosa. Ocultação inicial deu lugar a contenção do vírus. In O Globo, 20/03/20.

BATISTA JR., João. 'Exu corona', empréstimo para o dízimo e semente milagrosa contra Covid. In https://veja.abril.com.br/blog/veja-gente/exu-corona-emprestimopara-o-dizimo-e-semente-milagrosa-contra-a-covid/. Acesso em: maio de 2020

BITENCOURT, Cezar Roberto. Tratado de Direito Penal. Parte Especial. Vol. 4. 7a ed. São Paulo: Saraiva, 2013. 
DELMANTO, Celso et al. Código Penal comentado e acompanhado de comentário, jurisprudência, súmulas em matéria penal e legislação complementar. 8a ed. São Paulo: Saraiva, 2010.

FRANCO, Alberto Silva et al. Código Penal e sua interpretação jurisprudencial. Vol. 2. Parte Especial. 7ª ed. São Paulo: Revista dos Tribunais, 2001.

HUNGRIA, Nélson. Comentários ao Código Penal. Vol. IX. Rio de Janeiro: Forense, 1959.

JESUS, Damásio E. de. Direito Penal. Parte Especial. 3ํㅡㄴ Vol. 20ª Ed. São Paulo: Saraiva, 2012.

NUCCI, Guilherme de Souza. Código Penal Comentado. 14ª ed. Rio de Janeiro: Forense, 2014.

PANOEIRO, José Maria; NEVES, Elisa Ramos Pittaro. O Direito Penal em tempos de pandemia: A violação ao isolamento social determinado por autoridades estaduais e municipais constitui crime? CPJM Especial COVID-19. In

http://www.cpjm-uerj.rio.br/special-covid19/. Acesso em: maio de 2020

PRADO, Luiz Regis. Curso de Direito Penal Brasileiro. 9ª ed. São Paulo: Revista dos Tribunais, 2010.

SILVA, Antonio de Moraes. Diccionario da lingua portugueza. Lisboa: Borel, Borel e Cia., 1858.

SOUZA, Artur de Brito Gueiros; JAPIASSÚ, Carlos Eduardo A. Direito Penal. Volume Único. 2ª ed. São Paulo: Atlas, 2020.

; __ O O novo coronavírus e o Direito Penal. In

http://genjuridico.com.br/2020/04/06/novo-coronavirus-crime-de-epidemia/.

Acesso em: maio de 2020. 